\title{
The Fluoro-Pauson-Khand Reaction in the Synthesis of Enantioenriched Nitrogenated Bicycles Bearing a Quaternary C-F Stereogenic Center.
}

\author{
Alberto Llobat,,$^{\dagger}$ Raquel Román, ${ }^{\dagger}$ Natalia Mateu, ${ }^{* \dagger}$ Daniel M. Sedgwick, ${ }^{\dagger}$ Pablo Barrio, ${ }^{\natural}$ Mercedes Me- \\ dio-Simón $*^{\dagger}$ and Santos Fustero* ${ }^{\dagger \dagger}$ \\ † Departmento de Química Orgánica, Universitat de València, 46100 Burjassot, Spain \\ *Laboratorio de Moléculas Orgánicas, Centro de Investigación Príncipe Felipe, 46012 Valencia, Spain \\ 'Departamento de Química Orgánica e Inorgánica, Avda. Julián Clavería no 8, 33006 Oviedo, Spain \\ Supporting Information Placeholder
}

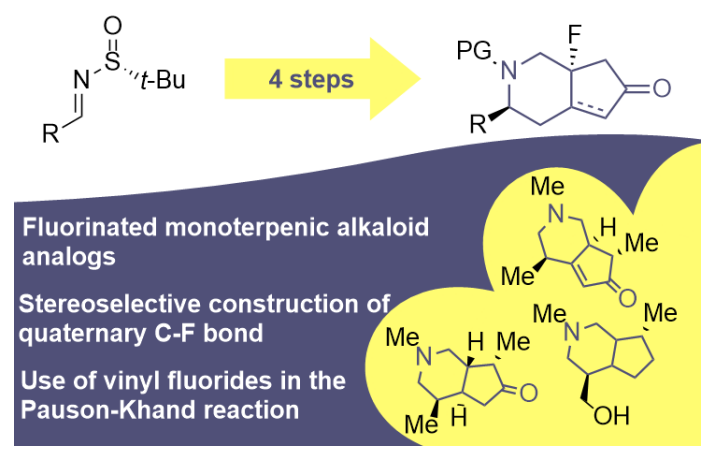

\begin{abstract}
A variety of enantioenriched fluorinated $6 H$-cyclopenta[c]pyridin-6-one bicycles, a scaffold present in several classes of monoterpenic alkaloids with varied biological activity, were synthesized in just five steps starting from simple aldehyde starting materials. The synthesis presented wide functional group tolerance and moderate to high yields and diastereoselectivities, and could be carried out at gram-scale. These products were suitable for further transformations, such as hydrogenation and deprotection of the tert-butyl sulfonyl protecting group.
\end{abstract}

Nitrogen-containing heterocycles are highly prevalent in pharmaceuticals and agrochemicals, as well as in other bioactive molecules. This is immediately apparent when considering the alkaloid class of natural products; morphine, caffeine, nicotine, and atropine all belong to this diverse family and present a wide range of biological activities. A somewhat understudied scaffold is the cyclopenta $[c]$ pyridin-6-one bicycle, present in various natural products such as Tecomanine, Tecostanine and certain compounds belonging to the Kinabalurine series (Figure 1). ${ }^{1,2}$ Both Tecomanine and Tecostanine are present in the leaves of Tecoma stans, a species of bush native to Latin America, infusions of which have long been used in Mexico to treat symptoms of diabetes. In fact, extracts of this plant have been shown to exert a significant hypoglycemic response in both rabbits and dogs, attributed to the action of these two monoterpenic alkaloids. ${ }^{3,4}$ Given this activity, compounds presenting this bicyclic structure could be useful in the search for new antidiabetic compounds; a class of pharmaceuticals that is increasingly important in the modern world..$^{5}$

In terms of synthesis, racemic Tecomanine has been synthesized through a variety of synthetic methods, including a Pauson-Khand reaction which allows the prior introduction of all necessary substituents directly into the precursor, creating the bicyclic molecular complexity in just one reaction (Scheme 1a). ${ }^{6}$ Series of enantioenriched products with similar structures have been prepared by both Gais ${ }^{7}$ and Evans, ${ }^{1}$ again through the use of a Pauson-Khand reaction as the key step to form the bicyclic scaffold.

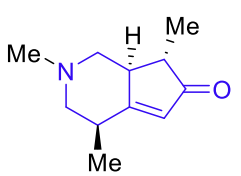

Tecomanine<smiles>[CH][C@H]1[C@H]2CN(C)C[CH][C@@H]1C[C@@H]2O</smiles>

Kinabalurine A<smiles>C[C@@H]1CCC2C(CO)CN(C)C[C@@H]21</smiles>

Tecostanine

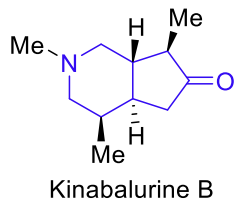

Figure 1. Structures of monoterpenic alkaloids bearing the target bicyclic structure. 
On the other hand, fluorine has become increasingly important in several key industrial fields, including but not limited to medicinal and pharmaceutical chemistry, agrochemistry and materials science. The strategic incorporation of fluorine into biologically active molecules can improve the drug-like properties of a given compound, such as the metabolic stability or lipophilicity. ${ }^{8-10}$ However, given the scarcity of natural products containing fluorine atoms, any advance in this field relies on the development of new methodologies to synthesize new fluorinebearing structures. A recent trend in medicinal organic chemistry, denominated the escape from flatland, refers to a shift from the more common aromatic and similar $\mathrm{C}_{\mathrm{sp} 2}$ tethers towards $\mathrm{C}_{\mathrm{sp} 3}$ carbon centers in an attempt to provide greater 3D molecular diversity. ${ }^{11}$ In particular, after approximately a decade of exhaustive research on the formation of $\mathrm{C}_{\mathrm{sp} 2}-\mathrm{F}$ and $\mathrm{C}_{\mathrm{sp} 2}-\mathrm{R}_{\mathrm{F}}$ bonds, ${ }^{12}$ the asymmetric introduction of fluorine or fluorinated groupings into $\mathrm{sp}^{3}$ carbon centers is gaining more attention in recent years. ${ }^{13}$ Regarding this objective, perhaps the most challenging is the selective construction of a quaternary stereogenic carbon center containing a $\mathrm{C}-\mathrm{F}$ bond. In fact, pharmaceutical drugs containing a stereogenic $\mathrm{C}-\mathrm{F}$ bond constitute just $1 \%$ of the drugs currently on the market as a direct result of this problem.

We recently reported the first Pauson-Khand reactions using enyne substrates containing a vinyl fluoride moiety as the olefin coupling partner, an effective way to construct molecular complexity and the coveted quaternary $\mathrm{C}-\mathrm{F}$ group in one step, albeit in a racemic manner. ${ }^{14}$ Owing to the complete diastereoselectivity observed in this process, we foresaw that enantiopure products bearing a stereodefined quaternary $\mathrm{C}-\mathrm{F}$ unit within a similar monoterpenic skeleton could be obtained by using a suitable enantioenriched substrate.

Scheme 1. a, b) Previous related work; racemic synthesis of Tecomanine precursor and other trifluoromethylated derivatives via the Pauson-Khand reaction. c) This work; the synthesis of enantioenriched fluorinated Tecomanine analogues.

a) Racemic synthesis of Tecomanine precursor ${ }^{6}$

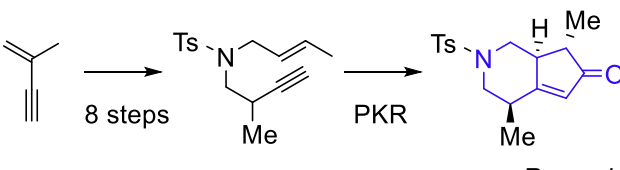

Racemic

b) Synthesis of trifluoromethyl-bearing Tecomanine analogue $^{15}$

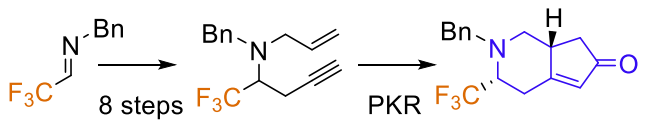

trans/cis: $85 / 15$

Racemic, only one example

c) This work

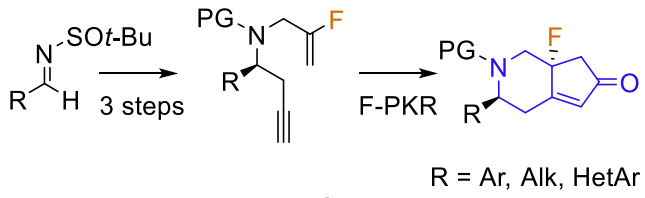

Single enantiomer obtained
We were surprised to find that fluorinated examples of this class of structure had not yet been studied, the only example in the literature being a single racemic analogue based on the same $6 H$-cyclopenta[ $c$ ]pyridin-6-one scaffold bearing a trifluoromethyl substituent, which was also synthesized using the PausonKhand reaction (Scheme 1b). ${ }^{15}$

Therefore, we decided to apply our method to the synthesis of enantioenriched compounds presenting the same bicyclic skeleton as seen in the aforementioned natural products, bearing an all-important $\mathrm{C}-\mathrm{F}$ bond at the bridged stereogenic center (Scheme 1c).

We first carried out a retrosynthetic analysis of our target structures (Scheme 2). The bicyclic core could be constructed via fluoro-Pauson-Khand reaction of the $\mathrm{N}$-tethered fluoroenyne precursor. The vinyl fluoride could be introduced using a suitable building block for the alkylation of the amine group, which could in turn be synthesized through stereoselective propargylation to the corresponding imine.

Scheme 2. Retrosynthetic analysis of target bicyclic structures.
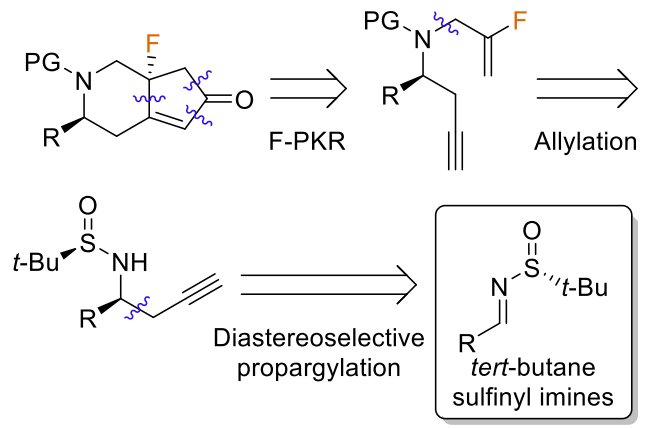

We then decided that Ellman's tert-butane sulfinyl imines would be suitable starting materials for our goal of synthesising Tecomanine analogues, since they can be used as electrophiles in many diastereoselective addition reactions with a variety of nucleophiles such as organometallic reagents. ${ }^{16,17}$ Specifically, the diastereoselective addition of propargyl magnesium bromide to this class of imines is well documented. Therefore, we followed the procedure reported by Zhang et al. to obtain a variety of sulfinylamide intermediates $\mathbf{2}$ in good yields and high diastereoselectivities. ${ }^{18}$ Aromatic, heteroaromatic and aliphatic aldimines participated in the propargylation step uneventfully with the exception of pyridine-based substrate $\mathbf{1} \mathbf{j}$, which resulted in a lower yield (See Supporting Information for details).

From there, the final step to form the precursors for the Pauson-Khand reaction was the introduction of the fluoroallyl group via alkylation of the nitrogen atom. Unfortunately, the direct alkylation of the sulfinylamides resulted in unsatisfactory yields $(<20 \%)$. However, we found that after oxidation to the corresponding sulfonamides, the reaction took place much more successfully. ${ }^{19}$ In this way, a series of $N$-tethered fluorinated enynes 4 was synthesized in good to high yields (Scheme 3).

Scheme 3. Synthesis of fluoro-Pauson-Khand precursors 4. 


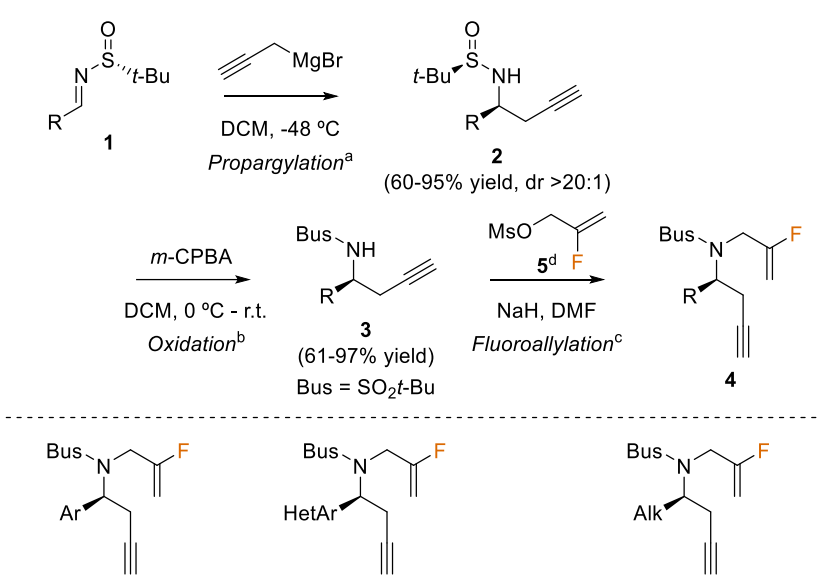

4a, $\mathrm{Ar}=\mathrm{C}_{6} \mathrm{H}_{5}, 72 \% \quad \mathbf{4 g}, \mathrm{Het} \mathrm{Ar}=3-$ Benzofuranyl, $84 \% \quad \mathbf{4 k}$, Alk $=c-\mathrm{C}_{6} \mathrm{H}_{11}, 95 \%$ 4b, $\mathrm{Ar}=4-\mathrm{MeC}_{6} \mathrm{H}_{4}, 45 \% \quad 4 \mathrm{~h}, \mathrm{HetAr}=2-$ Thiophenyl, $76 \% \quad 4 \mathrm{l}$, Alk $=c-\mathrm{C}_{3} \mathrm{H}_{5}, 82 \%$ 4c, $\mathrm{Ar}=4-\mathrm{OMeC}_{6} \mathrm{H}_{4}, 83 \% \quad 4 \mathrm{i}$, $\mathrm{HetAr}=3-\mathrm{Thiophenyl,} 71 \% \quad 4 \mathrm{~m}, \mathrm{Alk}=\mathrm{Ph}\left(\mathrm{CH}_{2}\right)_{2}, 94 \%$ 4d, $\mathrm{Ar}=4-\mathrm{t}-\mathrm{BuC}_{6} \mathrm{H}_{4}, 60 \% \quad 4 \mathrm{j}$, HetAr $=3$-Pyridinyl, $46 \%{ }^{\mathrm{e}} \quad 4 \mathrm{n}, \mathrm{Alk}=n-\mathrm{C}_{6} \mathrm{H}_{13}, 84 \%$ 4e, $\mathrm{Ar}=3-\mathrm{OMeC}_{6} \mathrm{H}_{4}, 75 \%$ 4e, $\mathrm{Ar}=3-\mathrm{OMeC}_{6} \mathrm{H}_{4}, 75 \%$
$\mathbf{4 f}, \mathrm{Ar}=4-\mathrm{BrC}_{6} \mathrm{H}_{4}, 50 \%$

Yields refer to the isolated yields of the final fluoroallylation step. ${ }^{\text {a }}$ Reaction carried out as described by Zhang et al. ${ }^{18}$ Standard conditions for the propargylation step: aldimine 1 (1 equiv), freshly prepared propargyl magnesium bromide ( 1.5 equiv), dichloromethane $(0.1 \mathrm{M}),-48{ }^{\circ} \mathrm{C}, 16 \mathrm{~h} .{ }^{\mathrm{b}}$ Standard conditions for the oxidation step: 2 (1 equiv), $m$-CPBA (1.2 equiv), dichloromethane $(0.1 \mathrm{M}), 0{ }^{\circ} \mathrm{C}-$ r.t., $2 \mathrm{~h}$. ${ }^{\mathrm{c}}$ Standard conditions for the fluoroallylation step: 3 ( 1 equiv), $\mathrm{NaH}$ ( 3 equiv), 5 ( 2 equiv), DMF $(0.2 \mathrm{M}), 0^{\circ} \mathrm{C}$ - r.t., 16 h. ${ }^{\mathrm{d}}$ Mesylate 5 prepared following the procedure described by Mykhailiuk et al. ${ }^{20 \mathrm{e}}$ An extra reduction step was necessary for the synthesis of $\mathbf{4 j}$ (see Supporting Information for details).

We then applied our fluoro-Pauson-Khand procedure to the desired precursors 4 (Scheme 4). ${ }^{14}$ However, our previously reported conditions using dichloromethane at $40{ }^{\circ} \mathrm{C}$ for the second reaction step were unsuccessful for these substrates. Instead, we found we had to switch the solvent to dichloroethane and increase the temperature slightly to $65^{\circ} \mathrm{C}$. The final bicyclic products were obtained in moderate to good yields and excellent diastereoselectivities $(\mathrm{dr}>20: 1)$. The reaction was tolerant of a variety of electron-neutral and electron-rich aromatic rings with several substitution patterns (6a-e). The presence of a halogen atom on the aromatic ring was also tolerated (6f). Heteroaromatic substituents at the stereogenic center resulted in interesting scaffolds combining two potential pharmacophores (6g-j). However, pyridine-based $\mathbf{6 j}$ resulted in a low yield. Substrates derived from aliphatic aldehydes, both linear and cyclic, were also successfully used (6k-n). The absolute stereochemistry of product $\mathbf{6 a}$ was determined to be $(S, R)$ by X-ray crystallography (see Supporting Information for details) (Scheme 4). ${ }^{22}$

The double bond in the resulting bicyclic products 6 could be efficiently and diastereoselectively ( $\mathrm{dr}>20: 1)$ hydrogenated using palladium over activated charcoal under an atmosphere of hydrogen. ${ }^{23}$ However, it is worth noting that the resulting saturated product 7 was unstable in acidic conditions, and rapidly lost HF during column chromatography using both standard silica gel and aluminum oxide (Scheme 5a).

\section{Scheme 4. Scope and limitations of the fluoro-Pauson-} Khand reaction
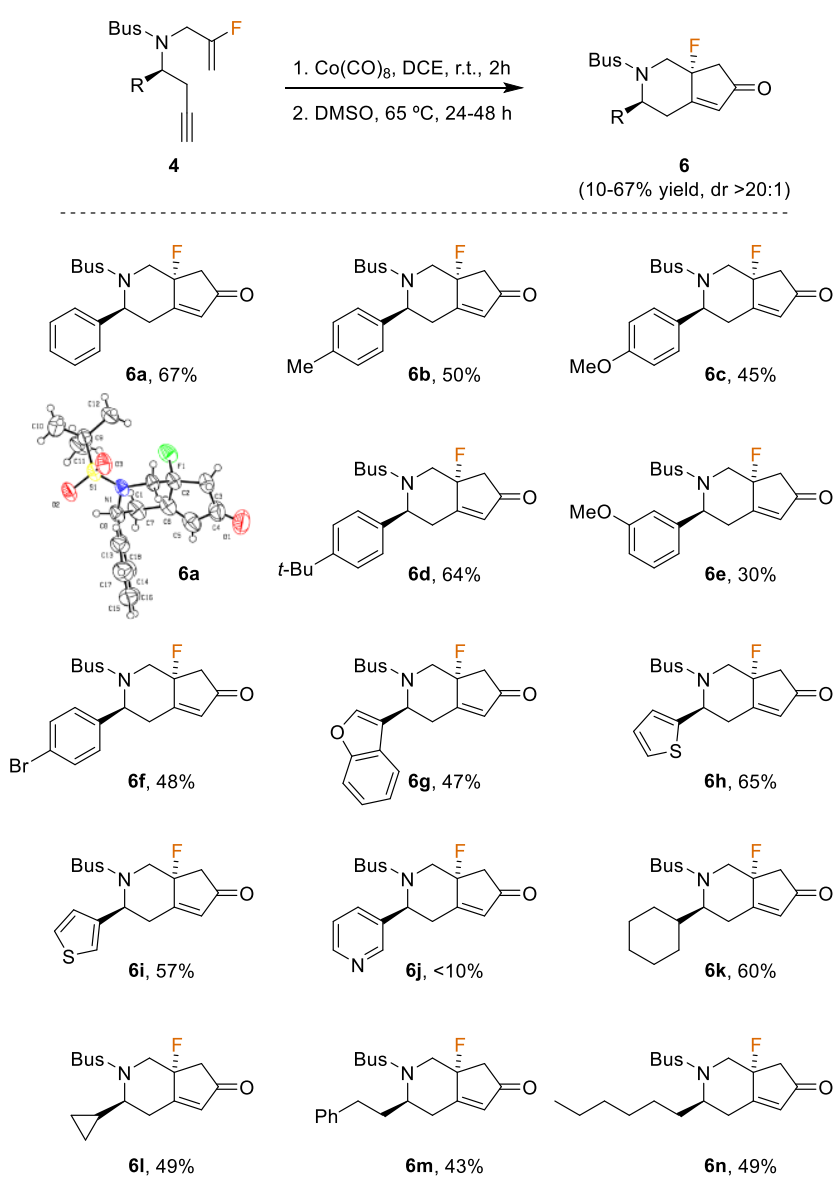

$61,49 \%$

$6 m, 43 \%$

6 n, $49 \%$

Nonetheless, using FluoroFlash® silica gel we were able to purify the desired saturated cyclopentanones 7 successfully, with no loss of HF. Furthermore, the tert-butyl sulfonyl group could be removed through treatment of the resulting Pauson-Khand adduct with trifluoromethylsulfonic acid in the presence of anisole to form $\mathbf{8}$ (Scheme 5a). ${ }^{24}$ The resulting amine was isolated as the hydrochloride salt, as the intermediate free amine was found to be unstable. A gram-scale synthesis of $\mathbf{6 a}$ was carried out successfully in good yield and no detectable decrease diastereoselectivity (Scheme 5b).

In summary, the power of the intramolecular Pauson-Khand reaction for the stereoselective construction of enantioenriched bicyclic cyclopentenones has been showcased by the concise asymmetric synthesis of fluorinated Tecomanine derivatives. Noteworthy is the use of vinyl fluorides as olefin counterparts in the Pauson-Khand reaction, allowing the stereoselective introduction of a fluorine atom in an otherwise synthetically challenging bridgehead quaternary stereocenter. Several synthetic transformations have been carried out on the obtained products, including hydrogenation of the unsaturated bicyclic system to generate the corresponding saturated derivative, and the removal of the Bus protecting group. A gram-scale synthesis has also been successfully achieved in five steps starting from the corresponding aldehyde.

Scheme 5. a) Examples of further modifications to the final Pauson-Khand adducts. b) Gram-scale synthesis of 6 a 
a)<smiles>CC(C)(C)N1CC2(F)CC(=O)C=C2CC1c1ccccc1</smiles><smiles>[Y7][R18](=O)c1ccccc1</smiles>

ii, iii

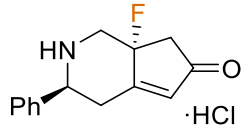

8, $93 \%$

Conditions: i) $\mathrm{Pd} / \mathrm{C}, \mathrm{H}_{2}$, EtOAc, r.t., 1 h. ii) $\mathrm{TfOH}$, PhOMe, DCM, $0^{\circ} \mathrm{C}, 1 \mathrm{~h}$. iii) $\mathrm{HCl}$-Dioxane, 30 mins

b)<smiles>O=Cc1ccccc1</smiles>

$1 \mathrm{~g}$

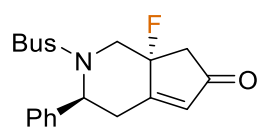

6a, $705 \mathrm{mg}$ (41\% global)

\section{ASSOCIATED CONTENT}

\section{Supporting Information}

The Supporting Information is available free of charge on the ACS Publications website at DOI:

Experimental procedures, characterization of all new compounds, and their corresponding NMR spectra (PDF).

\section{AUTHOR INFORMATION}

\section{Corresponding Authors}

* E-mail: santos.fustero@uv.es

* E-mail: natalia.mateu@uv.es

*E-mail.mercedes.medio@uv.es

ORCID

Santos Fustero: 0000-0002-7575-9439

Mercedes Medio-Simón: 0000-0001-9149-9350

Pablo Barrio: 0000-0001-7101-4037

\section{Author Contributions}

The manuscript was written through contributions of all authors. All authors have given approval to the final version of the manuscript.

\section{ACKNOWLEDGMENTS}

The authors are grateful to the Spanish MICINN and the AEI (CTQ2017-84249-P) for financial support, the SCSIE (Universitat de València) for access to instrumental facilities, and $\mathrm{M}$. R. Pedrosa (Universidad de Burgos) for providing us with $\mathrm{MoO}_{2} \mathrm{Cl}_{2}$. The technical and human support provided by SGIker (UPV/EHU, MINECO, GV/DJ, ERDF, and ESF) is also gratefully acknowledged. P. B. would like to thank the Spanish Ministry of Economy for a Ramón y Cajal contract (RyC-201620951). The authors are also grateful to Jose Cabeza for assistance in the synthesis of certain starting materials.

\section{REFERENCES}

(1) Kavanagh, Y.; O’Brien, M.; Evans, P. Stereocontrolled preparation of bicyclic alkaloid analogues: an approach towards the kinabalurine skeleton. Tetrahedron, 2009, 65, 8259-8268.
(2) Kam, T.-S.; Yoganathan, K.; Wei, C. Monoterpene Alkaloids from Kopsia pauciflora. J. Nat. Prod. 1997, 60, 673-676.

(3) Hammouda, Y.; Rashid, A.-K.; Amer, M.-S. Hypoglycaemic properties of tecomine and tecostanine. J. Pharm. Pharmacol. 1964, 16, 833-834.

(4) Lozoya-Meckes, M.; Mellado-Campos, V. Is the Tecoma Stans infusion an antidiabetic remedy? J. Ethnopharmacol. 1985, 14, 1-9.

(5) Lamos, E. M.; Hedrington, M.; Davis, S. N. An update on the safety and efficacy of oral antidiabetic drugs: DPP-4 inhibitors and SGLT-2 inhibitors. Expert Opin. Drug Saf. 2019, DOI: 10.1080/14740338.2019.1626823

(6) Ockey, D. A.; Lewis, M. A.; Schore, N. E. A short synthesis of ( \pm )Tecomanine via a Pauson-Khand-based route. Tetrahedron, 2003, 59, 5377-5381.

(7) Günter, M.; Gais, H.-J. Asymmetric Synthesis of Fused Bicyclic $\alpha$ Amino Acids Having a Hexahydro-cyclopenta[c]pyridine Skeleton via Intramolecular Pauson-Khand Reaction of 1-Sulfonimidoyl-Substituted 5Azaoct-1-en-7-ynes. J. Org. Chem. 2003, 68, 8037-8041.

(8) Purser, S.; Moore, P. M.; Swallow, S.; Gouverneur, V. Fluorine in Medicinal Chemistry. Chem. Soc. Rev. 2008, 37, 320-330.

(9) Wang, J.; Sánchez-Roselló, M.; Aceña, J. L.; del Pozo, C.; Sorochinsky, A. E.; Fustero, S.; Soloshonok, V. A.; Liu, H. Fluorine in Pharmaceutical Industry: Fluorine-Containing Drugs Introduced to the Market in the Last Decade (2001-2011). Chem. Rev. 2014, 114, 2432-2506.

(10) Yamazaki, T.; Taguchi, T.; Ojima, I. Unique Properties of Fluorine and Their Relevance to Medicinal Chemistry and Chemical Biology. In Fluorine in Medicinal Chemistry and Chemical Biology; Ojima, I., Ed; WileyBlackwell: Chippenham, 2009; pp 1-47.

(11) (a) Lovering, F. Escape from Flatland 2: complexity and promiscuity. MedChemComm, 2013, 4, 515-519. (b) Lovering, F.; Bikker, J.; Humblet, C. Escape from Flatland: Increasing Saturation as an Approach to Improving Clinical Success. J. Med. Chem. 2009, 52, 6752-6756.

(12) Neumann, C. N.; Ritter, T. Late-Stage Fluorination: Fancy Novelty or Useful Tool? Angew. Chem. Int. Ed. 2015, 54, 3216-3221.

(13) (a) Champagne, P. A.; Desroches, J.; Hamel, J.-D.; Vandamme, M.; Paquin, J.-F. Monofluorination of Organic Compounds: 10 Years of Innovation. Chem. Rev. 2015, 115, 9073-9174. (b) Zhu, Y.; Han, J.; Wang, J.; Shibata, N.; Sodeoka, M.; Soloshonok, V. A.; Coelho, J. A. S.; Toste, F. D. Modern Approaches for Asymmetric Construction of Carbon-Fluorine Quaternary Stereogenic Centers: Synthetic Challenges and Pharmaceutical Needs. Chem. Rev. 2018, 118, 3887-3964.

(14) Román, R.; Mateu, N.; López, I.; Medio-Simon, M.; Fustero, S.; Barrio, P. Vinyl Fluorides: Competent Olefinic Counterparts in the Intramolecular Pauson-Khand Reaction. Org. Lett. 2019, 21, 2569-2573.

(15) Magueur, G.; Legros, J.; Meyer, F.; Ourévitch, M.; Crousse, B.; Bonnet-Delpon, D. A One- Pot Synthesis of Doubly Unsaturated Trifluoromethyl Amines: Easy Access to $\mathrm{CF}_{3}$ - Substituted Piperidines. Eur. J. Org. Chem. 2005, 7, 1258-1265.

(16) Cogan, D. A.; Liu, G.; Ellman, J. Asymmetric synthesis of chiral amines by highly diastereoselective 1,2 -additions of organometallic reagents to $N$-tert-butanesulfinyl imines. Tetrahedron, 1999, 55, 8883-8904.

(17) Sedgwick, D. M.; Barrio, P.; Simón, T.; Román, R.; Fustero, S. Asymmetric Allylation/RCM-Mediated Synthesis of Fluorinated BenzoFused Bicyclic Homoallylic Amines As Dihydronaphthalene Derivatives. J. Org. Chem. 2016, 81, 8876-8887.

(18) Cui, L.; Li, C.; Zhang, L. A Modular, Efficient, and Stereoselective Synthesis of Substituted Piperidin-4-ols. Angew. Chem. Int. Ed. 2010, 49, 9178-9181.

(19) Hao, J.; Milcent, T.; Retailleau, P.; Soloshonok, V. A.; Ongeri, S.; Crousse, B. Asymmetric Synthesis of Cyclic Fluorinated Amino Acids. Eur. J. Org. Chem. 2018, 3688-3692.

(20) Tkachenko, A. N.; Radchenko, D. S.; Mykhailiuk, P. K.; Grygorenko, O. O.; Komarov, I. V. 4-Fluoro-2,4-methanoproline. Org. Lett. 2009, 11, 5674-5676.

(21) Rubio-Presa, R.; Fernández-Rodríguez, M. A.; Pedrosa, M. R.; Arnáiz, F. J.; Sanz, R. Molybdenum-Catalyzed Deoxygenation of Heteroaromatic $N$-Oxides and Hydroxides using Pinacol as Reducing Agent. Adv. Synth. Catal. 2017, 359, 1752-1757.

(22) The CCDC 1937096 contains the supplementary crystallographic data for $\mathbf{6 a}$. These data can be obtained free of charge from The Cambridge Crystallographic Data Centre via www.ccdc.cam.ac.uk/data_request/cif.

(23) The stereochemistry of 7 was tentatively assigned by a series of $2 \mathrm{D}$ NMR experiments.

(24) Sun, P.; Weinreb, S. M. tert-Butylsulfonyl (Bus), a New Protecting Group for Amines. J. Org. Chem. 1997, 62, 8604-8608. 
